Virtual Mentor. May 2004, Volume 6, Number 5.

doi: 10.1001/virtualmentor.2004.6.5.cprl1-0405

Clinical Pearl

\title{
Disaster Life Support
}

\section{The National Disaster Life Support Program offers courses that teach health professionals how to prioritize care and allocate medical resources in the event of a man -made or natural disaster.}

\author{
Julia C. Dombrowski, MD, MPH
}

Amidst all the discussion about the need for terrorism preparedness in the health care system, some of us are left wondering how to find training in disaster response. The National Disaster Life Support (NDLS) Program is one answer to this need. The courses offered by NDLS, including Basic and Advanced Disaster Life Support, were created in the vein of other nationally recognized training programs such as Advanced Cardiac Life Support $\mathbb{C}$. The class arms the learner with algorithms for a standardized response to "all-hazards," a group of man-made and natural disasters with the potential to cause multiple casualties. Key points of the algorithms are summarized here.

\section{Disaster Paradigm-D-I-S-A-S-T-E-R}

\section{D-Detection}

The first step in any response is awareness of a disaster, defined by NDLS as a situation where need exceeds the response capabilities. Sometimes detection is straightforward, but in the event of a biological attack, for instance, it may be more difficult. Detecting an event does not require an understanding of the cause.

\section{I-Incident Command}

This involves controlling the flow of resources available for response. An effective response requires multiple arms of operation with well-defined responsibilities, such as extrication and rescue, triage, transportation, and communications. The Incident Command System, originally designed for containing rapidly moving wildfires, is taught in NDLS classes.

\section{S-Scene Security and Safety}

The meaning of the saying, "when you arrive at a code, the first pulse you take should be your own," applies in disaster response too. Your own safety and that of your team must be your first concern. After all, if something happens to you, the number of victims goes up and an effective response is delayed even longer. Thereafter, your priorities should be the safety of the public (preventing more injuries), the patients, then the environment.

\section{A-Assess Hazards}

The disaster scene must be continually reassessed. You should have an awareness of the dangers that could potentially cause further injury, such as downed electrical lines and fires. Knowledge of the classic signs and symptoms caused by specific biological and chemical agents is helpful here. 


\section{S-Support}

As soon as possible, responders must pull in additional resources. Such support may include human resources, supplies, and vehicles. Although many well-intentioned volunteers and donations may appear, they are of little help in the absence of a coordinator and can be more of a liability than a support. Likewise, if you are interested in volunteering for disaster relief, you must find out ahead of time whether and how you can be useful.

\section{T-Triage and Treatment}

Disaster triage is potentially one of the most difficult aspects of disaster management. The M-A-S-S and Id-me algorithms below offer guidance on this task.

\section{E-Evacuation}

The short-term objective of disaster response is evacuation from the scene of the injured, then the uninjured who are without transportation, and finally rescue personnel. If very large numbers of people are involved in the disaster event, trains or school buses may be helpful in transporting people.

\section{R-Recovery}

This is the long-term objective of disaster response. Once the initial response is under way, responders will need to consider the long-term implications of the event on the injured, on rescue personnel, and on the environment. This may include crisis management counseling and shelter access.

\section{Triage/Treatment-M-A-S-S}

In a disaster situation involving multiple casualties, the level of injuries sustained by those involved may not be readily apparent. In this case, the Basic Disaster Life Support course offers the M-A-S-S algorithm as a 4-step method for triaging patients in order to allocate resources most effectively. The 4 steps produce 4 triage groups-immediate, delayed, minimum, and expectant, who should be attended to in that order. The groups are known by the acronym Idme.

\section{M-Move}

First announce, "Everyone who can hear me and needs medical attention, please move to the area with the green flag." The patients who move are in the minimal group. Next say, "Everyone who can hear me, please raise an arm or leg so we can come to you." This identifies the delayed group. The remaining patients are in the expectant and immediate groups.

\section{A-Assess}

Now you must differentiate between the expectant and immediate patients by assessing them individually. Do a quick survey of each patient. If his or her wounds are likely to be fatal, the patient is in the expectant group, and you must move on to identify people in the immediate group. This is a potentially difficult thing to do, but in a disaster-where by definition, needs outstrip resources — the axiom of doing the most good for the most people must hold.

\section{S-Sort}

Sort each of the patients into 1 of the 4 Id-me categories.

\section{S-Send}


Transport patients appropriately. Patients may be treated and released, transferred to hospitals, or sent to the morgue.

\section{Triage Categories-Id-me}

\section{I-Immediate}

Patients in this group have an obvious threat to life (eg, uncontrolled bleeding, or abdominal trauma with unstable vital signs), but can likely be saved.

\section{D-Delayed}

These are people who need care but are not likely to decompensate rapidly if treatment is delayed (eg, those with amputated fingers or open fractures).

\section{M-Minimal}

These patients would not have any serious ill effects even if care were delayed for days (eg, those with contusions or small abrasions).

\section{E-Expectant}

Patients in this group have little or no chance of survival, and the resources available for immediate patients cannot be diverted to their care. This designation does not mean that nothing can be done. Comfort care should be provided when possible, perhaps with the help of volunteers from the minimal group. The dead should be treated with respect, covered, and left with personal belongings. Bodies should not be moved, as doing so could destroy critical evidence.

Although the skills learned through these algorithms do not constitute comprehensive disaster preparedness, the NDLS courses do allow individuals to take personal responsibility for disaster preparedness. For more information on the classes, visit http://www.ama-assn.org/ama/pub/physician-resources/public-health/center-public-health-preparednessdisaster-response/ama-resources-policies.shtml. For registration information and a schedule of upcoming BDLS courses, see http://www.bdls.com or contact:

Center for Disaster Preparedness and Emergency Response

American Medical Association

515 North State Street

Chicago, IL 60610

James J. James, MD, DrPH, MHA, director

james_james@ama-assn.org

Francine Alexander, administrative assistant

francine_alexander@ama-assn.org

Jim Lyznicki, MS, MPH, senior scientist

jim_lyznicki@ama-assn.org

Ruth Steinbrecher, MPH, NDLS program administrator

ruth_steinbrecher@ama-assn.org

\section{Reference}


1. Coule PL, Dallas CE, James JJ, et al, eds. Chapter 1. In: Basic Disaster Life Support Provider Manual. V 2.5. Chicago, IL: American Medical Association; 2004.

Google Scholar

The viewpoints expressed on this site are those of the authors and do not necessarily reflect the views and policies of the AMA.

(C) 2004 American Medical Association. All Rights Reserved. 